\title{
Understanding the divide between the theory and practice of organisational change
}

Julien Pollack

University of Technology Sydney, Australia

DOI: http://dx.doi.org/10.5130/opm.v2i1.4401

\begin{abstract}
This paper reviews the different ways that academics and practitioners write about and discuss change management, to develop an understanding of whether there is a divide between the theory and practice of change management. This research used scientometric research techniques to compare three corpora: one based on the most cited research in the general management literature on change management; one based on the most cited research in specialist change management journals; and one based on interviews with practising change managers.
\end{abstract}

It was found that the general management literature emphasised an abstract understanding of knowledge management and the learning organisation, while the change management literature focused more on issues associated with value, culture and social identity. The practitioners emphasised issues at the individual, project and team levels, the need for the effective use of targeted communication to achieve organisational change objectives, and the value of rapidly identifying key drivers in a new context. This research found significant differences between these three corpora, which lends support to other researchers' claims of a divide between theory and practice in change management.

Keywords: Change Management; Theory; Practice; Text analysis; Scientometrics

\section{Introduction}

Organisational change management, both as topic of academic research and as a practical discipline, focuses on managing and understanding the ways that organisations adapt and change. The field draws on a broad literature on strategy, organisational development, human resources, and communication (Crawford \& Nahmais, 2010), having been influenced by works such as Phillips (1983), Connor (1993), and Kotter (1996). Professionals in the (C) 2015 Julien Pollack. This is an Open Access article distributed under the terms of the Creative Commons Attribution 4.0 Unported (CC BY 4.0) License (https://creativecommons.org/licenses/by/4.0/), allowing third parties to copy and redistribute the material in any medium or format and to remix, transform and build upon the material for any purpose, even commercially, provided the original work is properly cited and states its license. 
discipline are supported by industry associations like the Association of Change Management Professionals and the Change Management Institute, and academics have the opportunity to publish in specialist journals such as the Journal of Organizational Change Management and the Journal of Change Management.

Change management is becoming an increasingly significant topic for project management research and practice. The 2014 Project Management Institute Research and Education Conference included a dedicated track on change management, while the publication of Managing Change in Organizations: A Practice Guide (PMI 2013) suggests that change management is becoming part of the mainstream for project management practice. In addition, the inclusion of stakeholder management as a tenth knowledge area in the Guide to the Project Management Body of Knowledge (PMI 2013b) suggests that there is a general shift towards issues more commonly associated with change management in the normative project management literature, while Hornstein (2015) advocates for further integration between project management and change management.

There are a wide variety of techniques available for managing organisational change (Buchanan 1993, p.684; Stewart \& Kringas 2003, p.676; Sidorko 2008, p.307; Smith 2011, p.115; Pillay et al 2012, p.59). The discipline variously tends to focus on issues such as: organisational cultural development and change (Scott et al. 2003; Pless \& Maak 2004); changing organisational processes (Grover et al 1995; Chesbrough 2010); ways that leadership impacts on organisational changes (Pearce, 2004; Kavanagh \& Ashkanasy, 2006); and issues of resistance reduction and user acceptance, often in information technology projects (Legris et al 2003; Kramer \& Magee 1990). Readers who are interested in further analysis of the development of the field are referred to Cao and McHugh's (2005) detailed review.

As a result of the breadth of the field, change management is neither clearly defined or interpreted consistently. A variety of authors have found a divide between academics and practitioners about the nature of change management. For example, in 1993 Buchanan identified that boundaries existed between change management theory and practice (1993, p.684), and that the field was one where “... theory and recipe are typically unrecognizable to each other, and where the contrasting contributors tend to be dismissive of each other's approach” (1993, p.685). This sentiment has been echoed more recently, with Saka (2003, 
p.481) noting an "apparent mismatch between exhortation and action”, and Applebaum et al (2012, p.764) identifying a need for academics to bridge the theory-practice divide, "in order to translate current research into a format usable by practitioners”.

The research presented in this paper explores the change management literature and change managers' perspectives to test previous researchers' claims that there is a divide between change management theory and practice. This research makes no comment of the role of change management in the organisational change process. Rather, the relevance of the research to the project management community lies in developing a greater understanding of the nature of organisational change management. If project management theory and practice are to draw on change management, it is first necessary to understand it, before educated choices can be made about how and in which ways change management can be of benefit to the management of projects.

\section{Literature review}

As a way of exploring the divide between theory and practice in change management, this paper examines the ways that Kotter's (1996) Eight Stage Process of Creating a Major Change has been treated in the literature. This process is one of the most popular models for transforming organisations (Mento et al 2002, p.45). It has been referred to as the most compelling recipe for change management success (Phelan, 2005, p.47) and mainstream wisdom about how to manage change (Nitta et al 2009, p.467). Kotter's work "became a must read for organizational leaders planning and implementing change” (Brisson-Banks 2010, p.248), and "it remains a key reference in the field of change management" (Applebaum et al 2012, p.765).

Although a great deal is written about change management, there is evidence in the literature to suggest that researchers are either not conducting research that is relevant to the practice of change management, or are providing heuristics for practitioners without testing their impact. "Despite the abundance of literature with advice on change management for practitioners, a lack of research on how these practices work and on their effectiveness subsists" (Raineri 2011, p.267). This remains predominantly true for popular approaches to change, including Kotter's process. The thorough study of the literature conducted by Applebaum et al (2012) revealed that "most of the evidence found during the search points to data that has been compiled by Kotter himself” (p.776). Writers on change management seem to have discussed 
Kotter's process as if it had been tested and verified, with the popularity of the model more based on its accessibility than any scientific verification of its efficacy (p.764).

Applebaum et al (2012, p. 776) comment that there are very few academic case studies of organisational changes that were actually managed using Kotter's process. Review of the literature revealed only a few studies that examine the application of Kotter's process (e.g. Joffe \& Glynn 2002; Day \& Atkinson 2004; Ansari \& Bell 2009; Lintukangas et al 2009; Springer et al 2012; Pollack \& Pollack 2015), and in most of these cases the examination of Kotter's process remains more descriptive rather than critical. The majority of papers that make reference to Kotter's process do not present research on how the process can be used to effect organisational change. Instead, they discuss of Kotter's process in the broader context of the literature on organisational change, or how it is used as a framework for conducting a post-hoc analysis of an organisational change project (e.g. Yauch \& Steudel 2002; Sidorko 2008; Nitta et al 2009; Gupta 2011; Goede 2011; Smith 2011; Casey et al 2012).

If one of the most popular approaches to managing organisational change appears to remain largely unexamined by critical academic analysis, it is likely that this tendency may persist more broadly within the change management literature. Academic research has the potential to provide significant benefits to practitioners, as in being somewhat distanced from the immediacy of practical implementation researchers have the unique opportunity to abstract from practice, transferring learning between practice environments. However, without some engagement in the concerns and interests of those involved in practising change management, it is unlikely that there will be any substantial bridge over a divide between theory and practice.

\section{Research Method}

This research used scientometric techniques to compare key concepts in the general management literature on change management, the specialist change management literature, and practitioners' perspectives about their field. Scientometric research has been identified as being part of the larger field of information visualisation (Hook 2007, p. 442), and has also been referred to as knowledge domain visualisation, or domain mapping (Hook \& Börner 2005). This approach to research is quantitative, and is generally used to investigate networks of academic and scientific publications. These techniques have developed from studies that aimed to visualise domains based on citation ranking systems (Chen et al 2011, p. 131), and 
in general aim to develop holistic views of domains, highlighting structural details, or important characteristics of a domain, such as bursting concepts, dynamic changes, or pivotal contributors (Hook \& Börner 2005, p. 201).

The research presented in this paper has followed Börner’s (2010, p. 51) scientometric workflow design, as follows:

1. Data acquisition and pre-processing;

2. Analysis and modelling; and

3. Communication, visualisation and layout.

Data acquisition for this research involved two separate processes. A corpus representative of the general management literature on change management was developed based on the Scopus and ISI Web of Science databases. It has been identified that it is "hard if not impossible to identify and compare the entities (records and authors) from all contributing domains” Börner (2007, p. 814), and it is acknowledged that not all publications from the general management literature will have been included in this dataset. In particular, books published on change management will not have been included. However, these two databases are substantial, and for the purposes of this research the cross-section of these two comprehensive sources has been considered sufficiently broad to represent the general management literature on change management.

References that were potentially relevant to organisational change management were identified in these databases using the search term 'change management'. The results were sorted by the number of times they had been cited, and the records of the top 200 results were downloaded from both databases. Each record was then inspected to identify those that did not include abstract data, those that were not related to organisational change, and duplicate records. This left 105 records, published from 1979 to 2015. Most of the records that were deleted related to issues such as changes in medical patient management, engineering and software configuration management, and environmental and climate change. The corpus representative of the general management literature on change management was composed of the abstracts of these 105 influential papers. A second corpus was then constructed to represent the specialist academic change management literature. The records for the 100 most cited records in the Journal of Organizational Change Management and the Change 
Management Journal were downloaded. After deleting records that did not include abstract data, 189 records remained. The abstracts for these records formed the second corpus.

Interviews were held with change managers as a way of developing a third corpus representative of practitioners' views about change management. The interviews were semistructured, based on prompt questions asking the interviewees to describe change management and the experiences they had while managing change projects. Interviewees were initially selected from the author's personal contacts, and were chosen based on their experience and expertise in the field. A snowball approach was then used to source further interviewees, asking interviewees to suggest others whose abilities they respected. This approach facilitated contact with people who were respected by their peers, and acted as a surrogate for interviewee selection based on their competence in the discipline. A total of twelve interviews were conducted, with an average length of 65 minutes, and ranging in length from 50 minutes to 83 minutes. The transcripts of these interviews formed the practitioner corpus.

Identification of main themes and concepts in the three corpora was facilitated by LexiMancer software. LexiMancer software is used to process bodies of text to identify "word occurrence and co-occurrence counts to extract major thematic and conceptual content” (Angus et al 2013, p. 263). The software analyses frequencies of word cooccurrence to identify how significant words are, based on the context in which they are found. It assists in the identification of key concepts and themes, such as the research conducted by Biesenthal and Wilden (2014, p. 1292) on themes in project management governance research. Comparable studies have also been conducted by Middleton et al (2011) who used the LexiMancer software to analyse managers' narratives as a way of understanding how they perceive time, and by Cummings and Daellenbach (2005) who used the software to understand how the strategy and planning literatures are changing.

In this research, the first step in using the software involved a mostly automated process where the LexiMancer identified potentially significant concepts and themes in each corpus based on their frequency and centrality. Following this, an initial concept map of each corpus was created. The research then involved an iterative process of review and interpretation to understand the relevance of each concept based on the textual context in which it occurred, followed by regular redevelopment of the concept maps, to understand how each step 
changed the relationship between the concepts. Words that had been identified as potential key concepts, but that on analysis were demonstrated to be structural indicators, such as 'interviewer' and 'interviewee' were removed from the keyword lists. The keywords were read in context, to understand which keywords could be concatenated, as representing a single concept. This was most effectively done as a manual process, instead of using the automatic synonym function in the software. For instance, on review of the context in which the words were used, it appeared important to retain the distinction between 'organisation' and 'organisational' as these words were typically used in different ways. As a penultimate step, concepts were reviewed to identify joined concepts, based on their frequent cooccurrence. For example, ‘change' and 'management' were combined to create a third joint concept, as were 'business' and 'case', and 'organisational' and 'change'. The final step in the process focused on presentation, including the orientation of the diagrams, and theme sensitivity, to ensure that as far as possible concepts were clustered in appropriate theme groups.

\section{Results}

The LexiMancer software was used to create concept maps (Figures 1, 2, 3) based on the three corpora. In these maps, concepts are arranged so that the concepts that more frequently co-occurred in the text are placed closer to each other. Circle size indicates the relative frequency of the concepts in each corpus. The larger circles indicate clusters of concepts that LexiMancer refers to as themes. In each corpus, the following concepts were found to be consistently high frequency and central to the network graphs: change and management; change; management; business; process; time; and organisation. The consistent appearance of these concepts serves to provide some assurance that there are basic consistencies between the corpora and that they align with a natural language understanding of the field. 


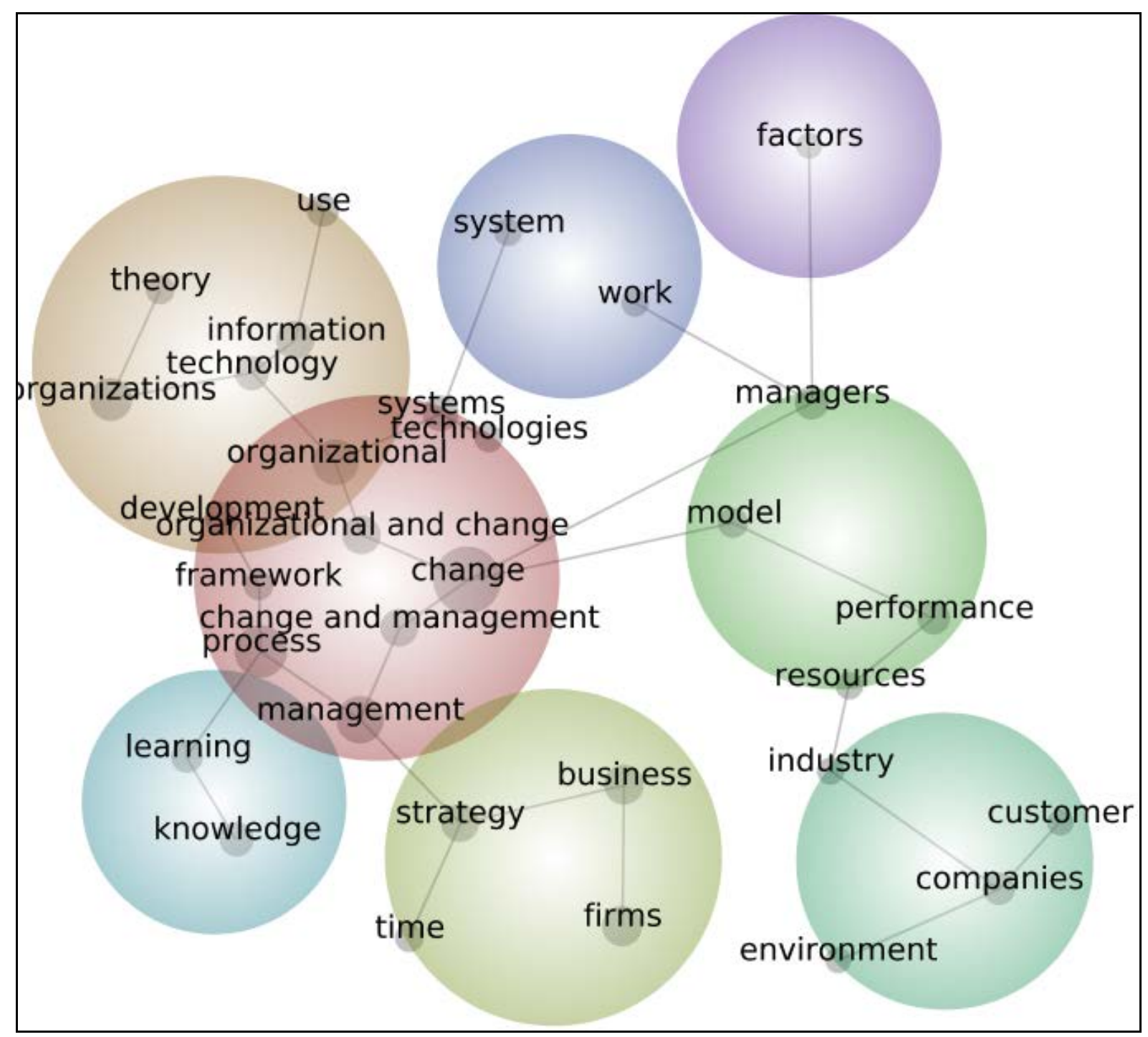

Figure 1. Concept map for the general management literature on change management

Initial differences between the practitioner and academic corpora are immediately apparent when similarities between the map of the general management literature (Figure 1) and the map of the specialist change management literature (Figure 2) are compared with the map of the practitioners' corpus (Figure 3). It is not surprising that the two academic corpora show an emphasis on theoretical issues, and that this is absent from the practitioners' corpus. 'Theory' and 'model' both feature in both academic corpora. The general management corpus also includes 'framework', while the specialist corpus features 'empirical' as one of the most significant concepts. These four concepts suggest a focus on the theoretical and abstraction that was not found in the practitioners' corpus. Although it is unsurprising to find a focus on these concepts in the academic corpus, it is interesting to note that these concepts were also absent at a lower level of analysis of the practitioners' corpus, suggesting that when 
describing change management, practitioners are not readily referring to theories about change in their conceptualisation of the activity.

It is also worthwhile noting that although 'organizational' and 'organizational and change' were significant concepts in both of the academic corpora, they did not appear as highly significant in the practitioners' corpus. These two concepts are relatively high frequency concepts in Figures 1 and 2, and they are consistently placed close to 'change and management', which suggests a high level of co-occurrence between these terms. From an academic's perspective, change management and organisational change appear to be highly connected concepts. However, 'organization and change' was not found to be a highly significant concept in the practitioners' corpus, indicating that the practitioners did not regularly mention this concept in the interviews. This suggests another broad division between the ways that practitioners and academics discuss change management. This is not to imply that the practitioners did not consider organisational issues when managing change, so much as that in the interviews they did not refer to change management issues as broader properties of their organisations. These results suggest that there are linguistic differences between these groups, which may be hampering communication and dissemination of knowledge. 


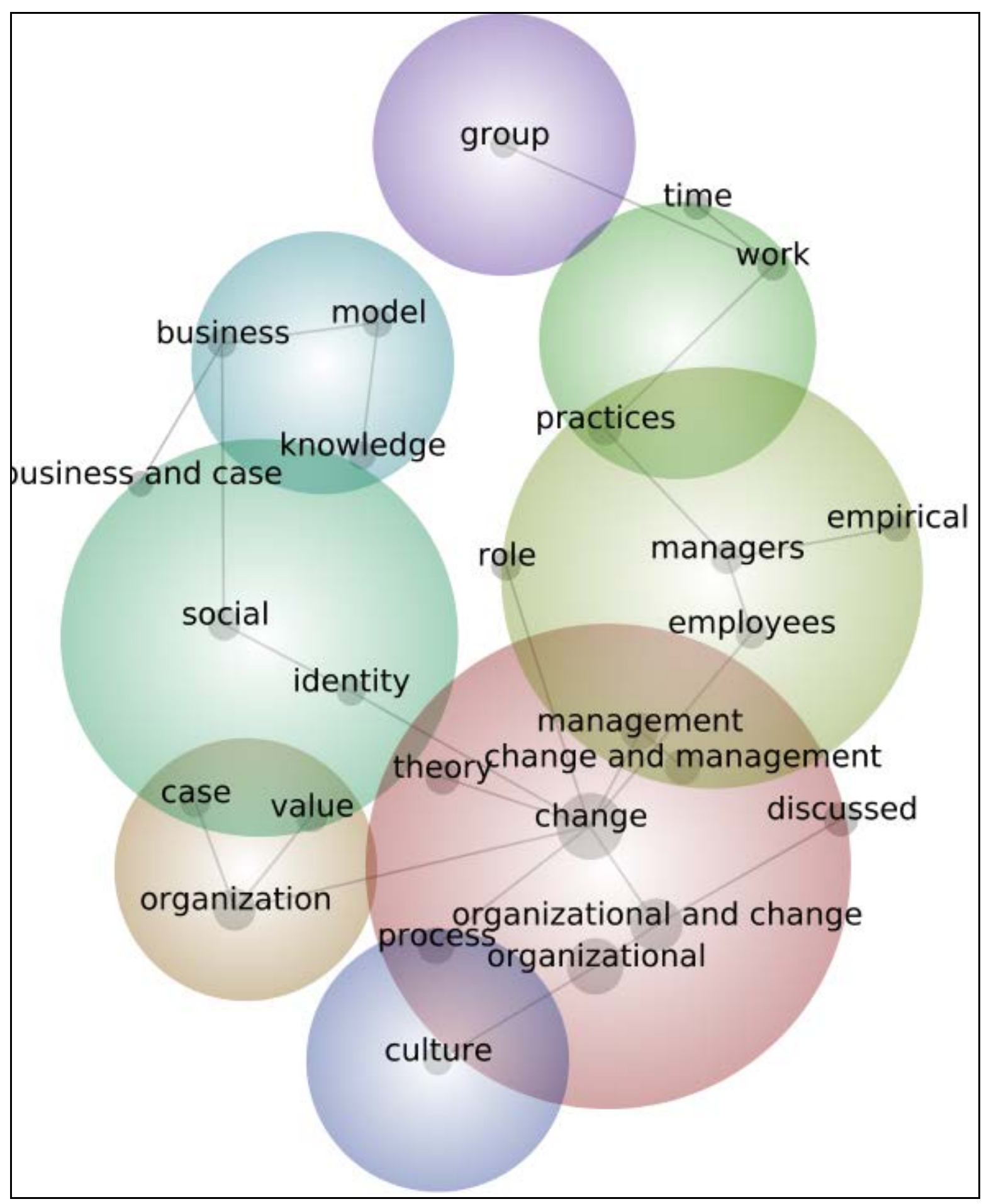

Figure 2. Concept map for the specialist literature on change management

It is also possible to develop an understanding about how these groups engage with the concepts of people and organisation, and the level of abstraction at which they discuss change management. 'Firm', 'performance’, ‘strategy', 'industry', and 'environment' were all significant concepts in the general management corpus. The general management texts tended to discuss the role of change management in strategy development and execution 
(Wiersema \& Bantel 1992; Barr et al 1992), business performance (Guzzo \& Dickson 1996; Cappelli \& Neumark 2001), and the way organisations respond to environmental or industrial change (Levinthal 1997).

Analysis of the specialist change management corpus revealed 'managers' and 'employees' as significant concepts. Many papers offered advice for managers, and some reviewed the impact of managers' ideologies or ethics on change. Texts in the corpus were found to examine the way that middle managers can contribute to the change process, particularly focusing on their resistance to, or participation in, the change process (Ole 2010; Teulier \& Rouleau 2013). Review of the way these concepts co-occurred showed that it was common to consider managers and employees as distinct groups. Review of the specialist corpus revealed that employees were often implied to be generic and potentially obstructive recipients of change (Michel et al 2010; Bridwell-Mitchell \& Mezias 2012).

In contrast, there was an emphasis on the particular and local in the practitioners' corpus. Significant concepts included ‘person', ‘people’, ‘team', 'group’, ‘project', and 'program’, all of which suggested that the interviewees were less focused on broad organisational issues than they were on the specific aspects of change projects, and management issues associated with the people involved in that process. 'Particular' also occurred as a significant concept, and when read in context, this concept was generally indicative of the interviewees' emphasis on the uniqueness of a particular change initiative, and the context-dependant issues that were involved. 'Company' was also found to be a high frequency concept, and the way this term was used was significantly different to the ways in which 'organization' and 'firm' were used in the academic corpora. While in the academic corpora these terms tended to be used to discuss organisations and firms as a general case, the practitioners instead focused on the localised history of an organisation, typically as a way of providing context for the organisational change they were relating.

Other general differences in focus were apparent between the corpora. For instance, the general management literature on change management tended to show an emphasis on 'learning', 'knowledge', and 'information', which revealed an emphasis on the links between change management, organisational learning and knowledge management (Gavin 1993). The specialist change management literature similarly showed a focus on knowledge management, but concepts such as 'social', 'value', 'culture', and 'identity' revealed that this 
was approached from a different perspective to that in the general management literature.

Review of how these concepts were used in the texts showed that there was a greater tendency towards sociological research (e.g. Dvir et al 2004) in the Journal of Change Management and the Journal of Organizational Change than was found in the general management literature on change management (Iveroth, 2011).

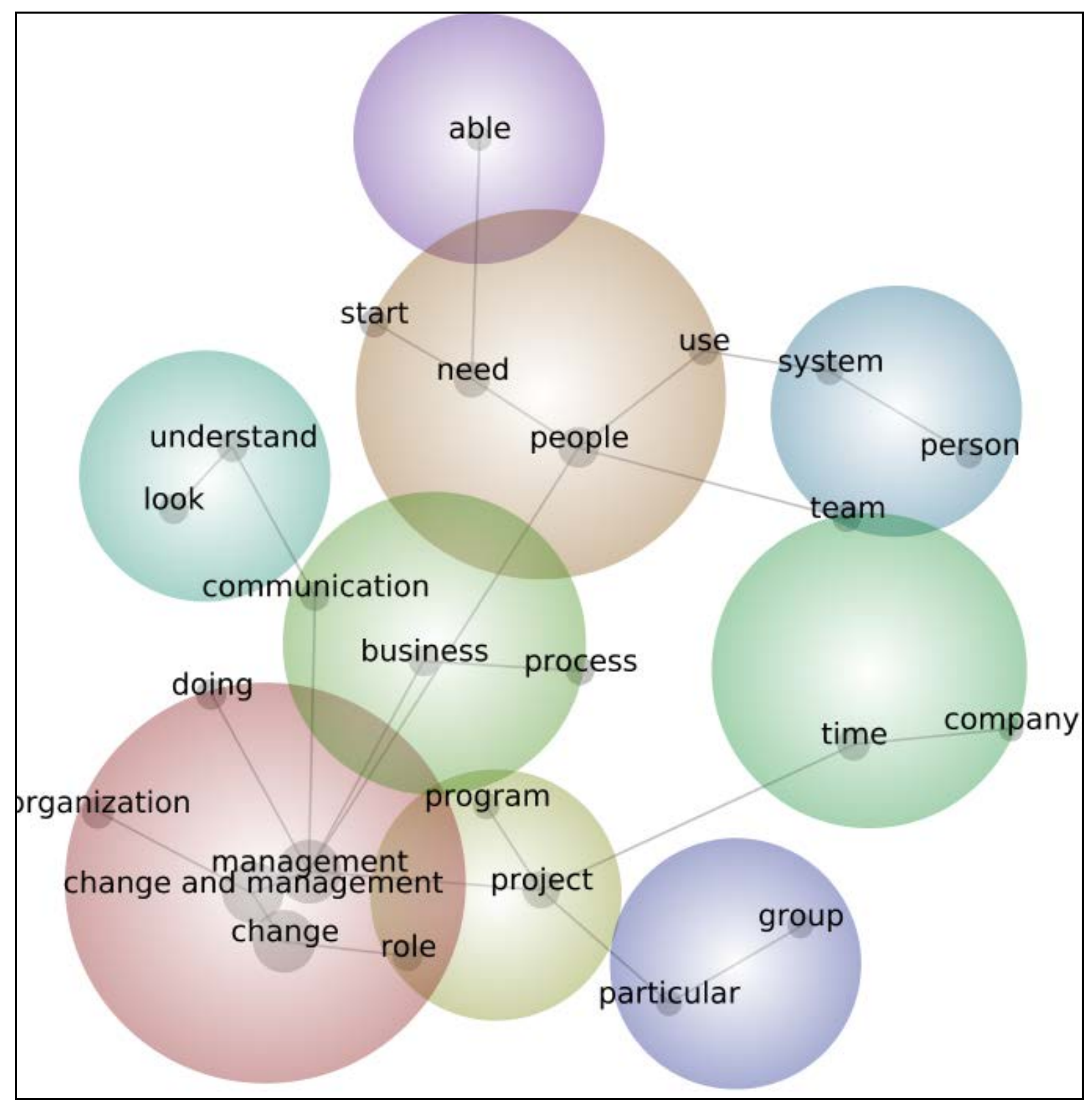

Figure 3. Concept map for the practitioner interviews

Review of the practitioners' corpus showed a different emphasis. When the terms were read in context, concepts like 'need', 'look', ‘understand', ‘doing', and 'able' suggested that the interviewees placed a great emphasis on the need to develop a rapid understanding of 
stakeholders needs and the local patterns of influence when starting on a change initiative. Exploration of the context-specific abilities of individuals involved in the change and the local work practices emerged as a strong theme, both with regard to what stakeholders to the change were currently doing, and potential future limitations or capacities. The change managers interviewed for this research discussed the need to develop a rapid understanding of the unique and particular context in which they were managing a change, before it was possible to understand where influence could most effectively be applied in guiding the change effort. In addition to an ability to quickly assess points of leverage and key contextual drivers, 'communication' was identified as a core capability for change managers. The interviewees regularly noted the need for change managers to effectively target their communication to influence key stakeholders and achieve the objectives of the organisational change project that they were working on.

\section{Limitations and future research}

There are two related limitations to the research presented here, both of which concern the data sources, and which provide opportunities for future research. The first limitation relates to the use of abstracts in the general management and specialist change management corpora as representative of the full intent of published research papers. In the developmental stages of this research, concepts maps were made including other downloadable database fields, such as the article titles and keywords. However, titles and keywords were later excluded, as they did not appear to be providing results that more accurately captured article content. While abstracts are typically written as a summary of an article, titles may be written as much to gain a potential reader's attention as to summarise the topic, and keywords are typically more of a matter for classification than complete description. It would have been preferable to use the full text of the identified research papers but, in many cases, particularly with older records, it was not possible to gain access to the article content in a form that could be processed. Future research may consider working with the full text of these papers when they become available in an appropriate format.

The second limitation of this research relates to the comparison of different kinds of research data. Published research papers were used as the basis for composing the two academic corpora, while interviews were used to form the practitioners' corpus. The use of text from articles on change management in professional trade publications was considered as a potential source that could represent the practitioners' perspective, but as it would not be 
obvious whether an article was written by a practitioner, or by an academic for a practitioner audience, this option was rejected. Another option would be to interview change management academics who do not also work in change management, and future research may wish to consider this as a potential data source.

\section{Conclusion}

The different emphases that practitioners and academics place on change management has been examined through the analysis of three corpora: one based on the abstracts from highly cited general management articles on change management; the second composed of the most cited articles in the specialist change management literature; and the third composed of the transcripts of interviews with practising change managers. It was found that there are significant differences between the corpora, which supports other researchers' claims that there is a divide between change management theory and practice.

Both academic corpora showed an emphasis on generalised models, theory and frameworks that was not apparent in the corpus based on interviews with the practitioners. Differences were also found in the way that the topic was discussed, with a regular use of the term 'organisational change' found in the academic corpora, but absent in the practitioners' corpus. The general management literature on change management emphasised abstract aspects of knowledge management and organisational learning, while the specialist change management literature more strongly emphasised understanding value, culture and identify from a sociological perspective. The interviews with change managers tended to focus on teams, individuals, and the practical specifics of managing change projects. Other themes in the practitioners' corpus included the need for change managers to use targeted communication to achieve objectives in their change projects, and the need to quickly become apprised of key drivers in a new context. These results suggest significantly different perspectives between how academics and practitioners discuss organisational change. Although the change management literature may be useful as a source of models and frameworks for understanding the activity of change management, it does not appear to be directly addressing the concerns of practitioners engaged in the management and delivery of organisational change projects. 


\section{Acknowledgement}

This paper is based on research presented at the International Conference on Business and Economic Development, New York, 2015. The author wishes to thank the conference participants for this feedback, which has contributed to the development of this paper.

\section{References}

Angus, D., Rintel, S. and Wiles, J., (2013), "Making senseof big text: a visual-first approach for analysing text data using Leximancer and Discursis", International Journal of Social Research Methodology, Vol. 16, No. 6, pp: 261-267. doi: http://dx.doi.org/10.1080/13645579.2013.774186.

Ansari, S., and Bell, J., (2009), "Five easy pieces: a case study of cost management as organizational change," Journal of Accounting and Organizational Change, Vol. 5, pp:139-167. doi: http://dx.doi.org/10.1108/18325910910963418.

Appelbaum, S., Habashy, S., Malo, J. and Shafiq, H., (2012), "Back to the future: revisiting Kotter's 1996 change model", Journal of Management Devleopment, Vol. 31, No. 8, pp: 764-782. doi: http://dx.doi.org/10.1108/02621711211253231.

Barr, P., Stimpert, J. and Huff, A., (1992), "Cognitive change, strategic action, and organizational renewal", Strategic Management Journal, Vol. 13, pp: 91-121. doi: http://dx.doi.org/10.1002/smj.4250131004.

Biesenthal, C. and Wilden, R., (2014), "Multi-level project governance: Trends and opportunities", International Journal of Project Management, Vol. 32, pp: 1291-1308.

doi: http://dx.doi.org/10.1016/j.ijproman.2014.06.005.

Cummings, S. and Daellenbach, U., (2009), "A Guide to the Future of Strategy?", Long Range Planning, Vol. 42, pp: 234-263. doi: http://dx.doi.org/10.1016/j.lrp.2008.12.005.

Börner, K., (2010), Atlas of Science: Visualizing What We Know, MIT Press, London.

Börner, K., (2007), "Making sense of mankind's scholarly knowledge and expertise: collecting, interlinking, and organizing what we know and different approaches to mapping (network) science", Environment and Planning B: Planning and Design, Vol. 34, pp: 808-825. doi: http://dx.doi.org/10.1068/b3302t.

Bridwell-Mitchell, E. and Mezias, S. (2012), "The Quest for Cognitive Legitimacy: Organizational Identity Crafting and Internal Stakeholder Support", Journal of Change Management, Vol. 12, No. 2, pp: 189-207. doi: http://dx.doi.org/10.1080/14697017.2011.645053.

Brisson-Banks, C., (2010), "Managing change and transitions: a comparison of different models and their commonalities," Library Management, Vol. 31, pp: 241-252. doi: http://dx.doi.org/10.1108/01435121011046317.

Buchanan, D., (1993), "Review of 'A Strategy of Change: Concepts and Controversies in the Management of Change", Journal of Management Studies, Vol. 30, No. 4, pp: 684-686.

Cao, G. and McHugh, M., (2005), "A Systemic View of Change Management and Its Conceptual Underpinnings", Systemic Practice and Action Research, Vol. 18, No. 5, pp: 475-490.

doi: http://dx.doi.org/10.1007/s11213-005-8484-4.

Cappelli, P. and Neumark, D., (2001), "Do 'high-performance' work practices improve establishment-level outcomes?", Industrial \& Labor Relations Review, Vol. 54, No. 4, pp: 737-775.

doi: http://dx.doi.org/10.2307/2696111. 
Casey, M., Payne, W., and Eime, R., (2012), "Organisational readiness and capacity building strategies of sporting organisations to promote health," Sport Management Review, Vol. 15, pp: 109-124.

doi: http://dx.doi.org/10.1016/j.smr.2011.01.001.

Chen, C., Fang, S. and Börner, K., (2011), "Mapping the development of scientometrics: 2002 to 2008", Journal of Library Science in China, Vol. 3, pp: 131-146.

Chesbrough, H. 2010, 'Business Model Innovation: Opportunities and Barriers', Long Range Planning, vol. 43, pp. 354-363. doi: http://dx.doi.org/10.1016/j.lrp.2009.07.010.

Connor, D., (1993), Managing at the Speed of Change. Random House.

Crawford, L. and Nahmais, A., (2010), "Competencies for managing change", International Journal of Project Management, Vol. 28, pp: 405-412. doi: http://dx.doi.org/10.1016/j.ijproman.2010.01.015.

Day, M., and Atkinson, D., (2004), "Large-scale transitional procurement change in the aerospace industry," Journal of Purchasing \& Supply Management, Vol. 10, pp: 257-268.

doi: http://dx.doi.org/10.1016/j.pursup.2004.10.003.

Dvir, T., Kass, N. and Shamir, B., (2004), "The emotional bond: vision and organizational commitment among high-tech employees", Journal of Organizational Change Management, Vol. 17, No. 2, pp: 126-143. doi: http://dx.doi.org/10.1108/09534810410530575. 91.

Garvin, D., (1993), "Building a Learning Organization", Harvard Business Review, Vol. 71, No. 4, pp: 78-

Grover, V., Jeong, S., Kettinger, W. and Teng, J., (1995), "The Implementation of Business Process Reengineering", Journal of Management Information Systems, Vol. 12, No. 1, pp: 109-144.

Goede, M., (2011), "Globalization of small islands: the role models of Curacao," International Journal of Commerce and Management, Vol. 21, pp: 192-212. doi: http://dx.doi.org/10.1108/10569211111144364.

Gupta, P. (2011), "Leading innovation change - the Kotter way," International Journal of Innovation Science, Vol. 3, pp.: 141-149. doi: http://dx.doi.org/10.1260/1757-2223.3.3.141.

Guzzo, R. and Dickson, M., (1996), "Teams in Organizations: Recent Research on Performance and Effectiveness, Annual Review of Psychology", Annual Review of Psychology, Vol. 47, pp: 307-338. doi: http://dx.doi.org/10.1146/annurev.psych.47.1.307.

Hook, P. and Börner, K., (2005), "Educational Knowledge Domain Visualizations: Tools to Navigate, Understand, and Internalize the Structure of Scholarly Knowledge and Expertise", in A. Spink and C. Cole (eds), New Directions in Cognitive Information Retrieval, Springer-Verlag, Netherlands, pp: 187-208. doi: http://dx.doi.org/10.1007/1-4020-4014-8_10.

Hook, P., (2007), "Domain Maps: Purposes, History, Parallels with Cartography, and Applications", 11th Annual Information Visualization International Conference, IEEE Computer Society Conference Publishing, Zurich, pp: 442-446. doi: http://dx.doi.org/10.1109/IV.2007.42.

Hornstein, H., (2015), "The integration of project management and organizational change management is now a necessity," International Journal of Project Management, 33, pp: 291-298. doi: http://dx.doi.org/10.1016/j.ijproman.2014.08.005.

Iveroth, E., (2011), "The sociomaterial practice of IT-enabled change: A case study of a global transformation", Journal of Change Management, Vol. 11, No. 3, pp: 375-395. doi: http://dx.doi.org/10.1080/14697017.2011.573490.

Joffe, M., and Glynn, S., (2002), "Facilitating change and empowering employees," Journal of Change Management, Vol. 2, pp: 369-379. doi: http://dx.doi.org/10.1080/714042517. 
Kavanagh, M. and Ashkanasy, N. (2006), "The Impact of Leadership and Change Management Strategy on Organizational Culture and Individual Acceptance of Change during a Merger", British Journal of Management, Vol. 17, pp: 81-103. doi: http://dx.doi.org/10.1111/j.1467-8551.2006.00480.x.

Kotter, J., (1996), Leading Change, Harvard Business School Press, Boston.

Kramer, J. and Magee, J., (1990), "The Evolving Philosophers Problem: Dynamic Change Management"', IEEE Transactions on Software Engineering, Vol. 16, No. 11, pp: 1293-1306. doi: http://dx.doi.org/10.1109/32.60317.

Legris, P., Ingham, J. and Collerette, P., (2003), "Why do people use information technology? A critical review of the technology acceptance model", Information \& Management, Vol. 40, pp: 191-204. doi: http://dx.doi.org/10.1016/S0378-7206(01)00143-4.

Levinthal, D., (1997), "Adaptation on Rugged landscapes", Management Science, Vol. 43, No. 7, pp: 934950. doi: http://dx.doi.org/10.1287/mnsc.43.7.934.

Lintukangas, K., Peltola, S., and Virolainen, V., (2009), "Some issues of supply management integration," Journal of Purchasing \& Supply Management, Vol. 15, pp: 240-248. doi: http://dx.doi.org/10.1016/j.pursup.2009.03.001.

Mento, A., Jones, R. and Dirndorfer, W., (2002), "A change management process: Grounded in both teory and practice", Journal of Change Management, Vol. 3, No. 1, pp: 45-59. doi: http://dx.doi.org/10.1080/714042520.

Michel, A., Stegmaier, R. and Sonntag, K., (2010), "I scratch your back - you scratch mine. do procedural justice and organizational identification matter for employees' cooperation during change?", Journal of Change Management, Vol. 10, No. 1, pp: 257-274. doi: http://dx.doi.org/10.1080/14697010903549432.

Middleton, S., Liesch, P. and Steen, J., (2011), "Organizing time: Internationalization narratives of executive managers", International Business Review, Vol. 20, pp: 136-150. doi: http://dx.doi.org/10.1016/j.ibusrev.2010.07.007.

Nitta, K., Wrobel, S., Howard, J., and Jimmerson-Eddings, E., (2009), "Leading change of a school district organization," Public Performance \& Management Review, Vol. 32, pp: 463-488. doi: http://dx.doi.org/10.2753/PMR1530-9576320305.

Ole, H., (2010), "The politics of middle management sensemaking and sensegiving", Journal of Change Management, Vol. 10, No. 2, pp: 195-215. doi: http://dx.doi.org/10.1080/14697011003795669.

Pearce, C. (2004), "The future of leadership: Combining vertical and shared leadership to transform knowledge work", Academy of Management Executive, Vol. 18, No. 1, pp: 47-57. doi: http://dx.doi.org/10.5465/AME.2004.12690298.

Phelan, M., (2005), "Cultural revitalization movements in organization change management," Journal of Change Management, 5, pp: 47-56. doi: http://dx.doi.org/10.1080/14697010500036106.

Pillay, J., Hackney, R., and Braganza, A., (2012), "Informing strategic IS change: towards a 'meta-learning' framework," Journal of Strategic Information Systems, Vol. 21, pp: 58-71.

doi: http://dx.doi.org/10.1016/j.jsis.2011.12.002.

Pless, N. and Maak, T., (2004), "Building an Inclusive Diversity Culture: Principles, Process and Practice", Journal of Business Ethics, Vol. 54, pp: 129-147. doi: http://dx.doi.org/10.1007/s10551-004-9465-8.

Phillips, J., (1983), "Enhancing the effectiveness of organizational change management," Human Resource Management, Vol. 22, No. 1-2, pp: 183-99. doi: http://dx.doi.org/10.1002/hrm.3930220125.

Pollack, J. and Pollack, R., (2015), "Using Kotter's Eight Stage Process to Manage an Organisational Change Program: Presentation and Practice," Systemic Practice and Action Research, 28, pp: 51-66. doi: http://dx.doi.org/10.1007/s11213-014-9317-0. 
Project Management Institute (PMI), (2013a), Managing Change in Organizations: A Practice Guide. Newtown Square, Project Management Institute.

Project Management Institute (PMI), (2013b), A Guide to the Project Management Body of Knowledge, 5th Edition. Newtown Square, Project Management Institute.

Raineri, A., (2011), "Change management practices: impact on perceived change results," Journal of Business Research, Vol. 64, pp: 266-272. doi: http://dx.doi.org/10.1016/j.jbusres.2009.11.011.

Saka, A. (2003), "Internal change agents' view of the management of change problem", Journal of Organizational Change Management, Vol. 16, No. 5, pp: 480-496. doi: http://dx.doi.org/10.1108/09534810310494892.

Scott, T., Mannion, R., Davies, H. and Marshall, M. (2003), "Implementing culture change in health care: theory and practice", International Journal for Quality in Health Care, Vol. 15, No. 2, pp: 111-118. doi: http://dx.doi.org/10.1093/intqhc/mzg021.

Sikorko, P., (2008), "Transforming library and higher education support services: can change models help?" Library Management, Vol. 29, pp: 307-318. doi: http://dx.doi.org/10.1108/01435120810869093.

Smith, I., (2011), "Organisational quality and organisational change: interconnecting paths to effectiveness," Library Management, Vol. 32, pp: 111-128. doi: http://dx.doi.org/10.1108/01435121111102629.

Springer, P., Clark, C., Strohfus, P., and Belcheir, M., (2012), "Using transformational change to improve organizational culture and climate in a school of nursing," Journal of Nursing Education, Vol. 51, pp: 81-88. doi: http://dx.doi.org/10.3928/01484834-20111230-02.

Stewart, J., Kringas, P., (2003), "Change management—strategy and values in six agencies from the Australian Public Service," Public Administration Review, Vol. 63, pp: 675-688. doi: http://dx.doi.org/10.1111/1540-6210.00331.

Teulier, R. and Rouleau, L. (2013), "Middle Managers' Sensemaking and Interorganizational Change Initiation: Translation Spaces and Editing Practices", Journal of Change Management, Vol. 13, No. 3, pp: 308337. doi: http://dx.doi.org/10.1080/14697017.2013.822674.

Wiersema, M. and Bantel, K., (1992), "Top management team demography and corporate strategic change", Academy of Management Journal, Vol. 35, No. 1, pp: 91-121. doi: http://dx.doi.org/10.2307/256474.

Yauch, C., and Steudel, H., (2002), "Cellular manufacturing for small businesses: key cultural factors that impact the conversion process," Journal of Operations Management, Vol. 20, pp: 593-617. doi: http://dx.doi.org/10.1016/S0272-6963(02)00029-3.

\section{About the Author}

Julien Pollack started working in project management in the Australian public sector delivering organizational change projects, where he completed an Action Research Ph.D. This research won national and international awards. Following this, he managed telecommunications and heavy engineering projects, before joining UTS in 2011 to teach in the Master of Project Management. His research has focused on two broad themes: trends in project management research; and developing project management practice to meet the needs of projects that cannot be pre-defined in simple and stable terms. He has successively drawn on systems thinking, complexity theory, and change management to address this latter area of research, particularly focusing on the delivery of organisational change projects. His research in these areas has been frequently published in the leading project management journals and research conferences. 